\title{
Federal budget disappoints on universal pharmacare
}

- Cite as: CMAJ 2019 April 8;191:E406-7. doi: 10.1503/cmaj.109-5736

Posted on cmajnews.com on Mar. 20, 2019.

$\mathrm{T}$ he 2019 federal budget lays the groundwork for universal pharmacare but stops short of commitments to a specific national plan. The budget also earmarks funds to address the opioid crisis, dementia and suicide prevention, among other health investments.

As a first step toward a national pharmacare program, the Trudeau government announced $\$ 35$ million over four years, starting in 2019, to create a national drug agency. The new agency will assess the effectiveness of prescription drugs, negotiate prices on behalf of Canada's drug plans, and develop a national formulary. To improve access to high-cost drugs for rare diseases, the government will also invest up to $\$ 1$ billion over two years, starting in 2020, and $\$ 500$ million a year thereafter.

These investments mark a "paradigm shift in the right direction," says Steve Morgan, a professor in the faculty of medicine at the University of British Columbia. "The risk is that they are small steps and it's relatively slow progress at the end of this mandate of the government."

Canadians pay some of the highest drug prices in the world, with brand-name medicines costing an average $20 \%$ more in Canada than in peer countries. Canada's patchwork of public and private drugs plans is part of the problem, says Morgan. "The most effective way to negotiate is through a national agency that buys on behalf of all purchasers in the system."

According to Dr. Danielle Martin, vicepresident of Women's College Hospital, a national drug agency and formulary are "core and crucial" to support a national pharmacare plan. On their own, however, "these are necessary but not sufficient steps."

"In the absence of a true pharmacare commitment in the budget, we're now heading for a pharmacare election," Martin says.

At a press conference, Finance Minister Bill Morneau said a pharmacare program can't be created overnight and Canadians will have to "stay tuned" for more details.

It's now looking like the government will hold off on announcing a plan until it receives the final recommendations of the Advisory Council on the Implementation of National Pharmacare in June. With a fall election on the horizon, "it would appear they're setting this up as essentially platform material," says Morgan.

It's a high stakes gamble. "Certainly, the election has a possibility to wreak havoc with this kind of policy," Morgan says. "If the Conservatives 
are elected into the federal government, the hopes of an evidence-based national pharmacare program are lost, because they've consistently opposed that kind of plan for the 22 years l've studied this file."

Other key health investments in the budget include:

- \$134.4 million over five years to improve food security;

- \$30.5 million over five years for harm reduction and treatment programs to reduce opioid deaths;

- $\$ 50$ million to the Public Health Agency of Canada to support a national dementia strategy;

- \$36.5 million over five years to Health Canada to develop a pan-Canadian data and performance system for organ donation and transplantation;

- Expanded tax relief for people experiencing infertility, using assisted reproduction methods, accessing multidisciplinary heath care services, or purchasing certain foot care devices;

- $\$ 25$ million over five years to support a
pan-Canadian, bilingual suicide prevention service;

- \$2.4 million over three years for research into reducing barriers to blood plasma donation;

- \$12 million over three years to support employment for people with autism; and

- \$13.7 million over five years to improve the accessibility of government workplaces.

Lauren Vogel, CMAJ 